which have an important medical component, the majority of these being in the psychiatric field.

The Samaritans were founded 21 years ago and today have nearly 150 branches in the British Isles, with some 18000 volunteers. They dealt with more than 192000 new self-referred clients in 1974. One of their great advantages is that they provide a 24-hour service and all the time that the client needs, either by telephone or face to face, without any delay. They are not experts or attached to any establishment but just ordinary men and women of all ages and social conditions who are accepted as volun teers because they have the special flair for establishing a warm, caring, and empathetic relationship which is basic to the Samaritan role. Selection, however, is strict and they are systematically prepared.

Nearly all the branches have a psychiatric consultant and a general practitioner adviser. In the many cases of depression and other psychiatric conditions their aim is always to get the client in touch with his own doctor as soon as possible and to maintain a close liaison with him-always, however, with the client's consent. Not infrequently doctors suggest to their patients that they should get in touch with the Samaritans for the special help that they can give.

Professor Aitken stresses that the clinica relationship is "the most powerful aid to reducing distress" and says, "it can bring about miracles." It is this relationship, operating in many cases in conjunction with the help of medical and social services, that the Samaritans aim to provide.-I am, etc.,

Poole, Dorset

DORIS ODLUM

\section{Treatment of Protein-losing} Gastroenteropathy

SIR,-Though several possible explanations of the mechanism of excessive enteric protein loss in "protein-losing gastroenteropathy" have been made, no definite treatment for the disease has yet been found except for the surgical resection of the affected digestive traot.

We have examined the gastric mucosa obtained by biopsy under fibrescopy from a 25-year-old man with erosive gastritis accompanied by hypoproteinemia and increased faecal 131 I-polyvinyl-pyrrolidone faecal excretion and found marked elevation of the activity of "tissue activator of plasminogen" (TA). ${ }^{1}$ The evidence suggested the possibility that the increased fibrinolytic activity in the gastric mucosa participates in the enhancement of mucosal permeability to protein. The patient was therefore treated by oral administration of a synthetic inhibitor of plasmin, trans-4-aminomethylcyclohexane carboxylic acid (tranexamic acid). ${ }^{2}$ In a month marked elevation of the serum protein level and a reduction of the mucous membrane disorder were observed. After treatment for three months no hypo proteinemia reappeared when placebo was given.

In a 22-year-old woman with Crohn's disease, though the TA activity of the small intestine could not be examined, tranexamic acid again had a dramatic effect in elevating the serum protein level, with reduction in the severe watery diarrhoea. In a 30-year-old man with Menetrier's disease biopsy of the gastric mucosa revealed high TA activity in parallel with a decrease in serum protein level. He underwent surgical resection of the stomach without a previous trial of tranexamic acid therapy since the presence of a submucosal tumour was suspected; this was not confirmed, however, by subsequen histological examination.

These three cases strongly support the new concept that increased TA activity, probably due to the underlying mucosal disorder, may play an important role in the pathogenesis of protein-losing gastroenteropathy.-We are, etc.,

MOTOHARU KONDO KEIMEI HOSOKAW MASASUKE MASUdA

Department of Medicine, Japan

1 Astrup, T., and Albrechtson, O. K., Scandinavian fournal of Clinical and Laboratory Investigation,
$1957,9,233$.

Okamoto, S., et al., Keio fournal of Medicine,
1964, 13, 177.

\section{Illness in the Clouds}

SIR,-Your leading article (8 February, p 295) gave a succinct review of the problem and also highlighted the predicament of those with pre-existing medical conditions who must be transported by air. It was notable from the B.O.A.C. figures ${ }^{1}$ that 47 of the 90 deaths were those of notified invalids. It is our experience that compliance with the conditions stated on the "medical certificate of fitness for air travel" is often taken as a protection against illness in flight.

During the past five years Transcare International has escorted 950 people on flights. Of these, 755 were on scheduled flights and 220 on air ambulance flights; 170 were acompanied by a doctor and 805 by a state registered nurse. There have been no deaths in the air or later attributable to transport of the patients. It would seem that the severely ill can be moved safely by air provided that their condition is stabilized before the flight, that close watch is made on their condition during flight, and that any abnormality arising is immediately corrected.-I am, etc.

\section{R. J. FAIRHURS} Medical Officer
Transcare Internationa

Croydon, Surrey

1 Richards, P. R. M.D. thesis, University of London, 1970.

\section{Heberden's Angina and Syncope Anginosa}

SIR,-It is a pity that the otherwise excellent report from Drs. J. B. Irving and A. H. Kitchin (8 March, p. 555) was marred by a complete distortion of the historical perspective of ischaemic heart disease. Heberden did not describe angina in relation to syncope but "giddiness, confusion, stupidity, inattention, forgetfulness and irresolution ... they either sink under it in a fainting fit, or it is with great efforts and struggling they can keep from it ...." under the heading of "hypochondriacus et hystericus affectus." The concept and the term "syncope anginosa" were described in 1799 by C. H Parry, ${ }^{2}$ himself an Edinburgh graduate.

Indeed, the confusion which has existed about angina pectoris vis-à-vis syncope anginosa and the inability of generations of physicians to distinguish between these disorders have contributed to our failure in the present day to understand the pathophysiology of ischaemic heart disease as expressed by these two conditions. Heberden's angina is commonly due to the effects of obstruction to blood flow by coronary arterial atherosclerosis during exercise-induced tachycardia, whereas Parry's syncope anginosa is associated with reduced tissue perfusion during bradycardiac dysrhythmias, as has been documented by Trousseau, Charcot, Allbutt, and others and reviewed in an account which resolves the Heberden-Parry controversy about the nature and pathogenesis of angina pectoris. ${ }^{3}$ Heberden's angina develops in active patients, Parry's syncope anginosa presents occasionally as intermittent claudication but more commonly in the less active elderly patient as repeated falls, fractures, sometimes strokes, and even dementia. ${ }^{4}$ - I am, etc.,

BRIAN LIVESLEY

Department of Medical History, King's College Hospital,

Heberden, W., Commentaries on the History and Cure of Diseases, p. 226. London, Payne, 1802 Parry, C. H., An Enquiry into the Symptoms and Called Angina Pectoris. Bath, Cruttwell, 1799 . Livesley, B., Medical History, 1975, 19, 158. Livesley, B. and Atkinson, L., Modern Geriatrics,
1974, 4, 458 .

\section{Kilo-what?}

SIR,-We have moved towards uneasy coexistence with kilojoules-perhaps partly because of the great opportunities for future advertising copy-writers ("a joule of a food" etc.)

We must, however, report that the kilopascal (8 February, p. 333) moved us to two apprehensive kilochaplins (basic units of amusement). Let us hope that the earnest purveyors of instantaneous logic in scientific measurement are neither too high on the kiloquixote scale (impossible dream units) nor likely to cause rising titres of kilokhans (international units of chaos and confusion, named after the amiable 13th century Jenghiz).-We are, etc.

DERRICK B. JELLIFFE E. F. Patrice Jelliffe

School of Public Health

University of California,

Los Angeles, California

SIR,-It is clear from the most recent correspondence from the "British Medical Association that only one issue now lies between the consultants and the Government, that is, as the secretary of the Central Committee for Hospital Medical Services says in his most recent letter to us, "the definition of the contractual commitments of whole-time and maximum part-time consultants, and the distinction between them."

The Government has already made quite considerable efforts to define, in terms of time worked, sessional commitments of consultants, and this leaves us clear to proceed to discussion of on-call and extra duty payments. The issue dividing consultants from 